\title{
Framing Research Questions Intersecting Information Systems and Health: A New Research Perspective at Micro- and Macro-Level
}

\author{
Maike Greve \\ University of Goettingen \\ maike.greve@uni-goettingen.de \\ Alfred Benedikt Brendel \\ University of Goettingen \\ abrende1@uni-goettingen.de
}

\author{
Morten Gantner \\ University of Goettingen \\ morten.gantner@uni-goettingen.de \\ Lutz Kolbe \\ University of Goettingen \\ lkobe@uni-goettingen.de
}

\author{
Christine Harnischmacher \\ University of Goettingen \\ christine.harnischmacher@uni- \\ goettingen.de
}

\begin{abstract}
Digital health is an established research area in information systems (IS) research. The domain involves individual human behavior, the broader social, healthcare providers, and other organizations. The rapid spread and use of health technologies have opened up considerable opportunities for research to evaluate and test existing theories. To generate an overview of the status quo, we apply the belief-actionoutcome (BAO) framework as a lens to understand how current research has addressed the various aspects of digital health. Overall, we analyzed 46 studies from well-regarded IS outlets. Therefore, we aim at providing a comprehensive review and synthesis of the literature. Our results indicate a focus on behavioral research and action formation, but also a void regarding design-oriented studies, as well as multi-level studies. In summary, this study develops a research agenda for digital health, which includes six research questions that address research focus, health phenomena, at the macro- and micro-level.
\end{abstract}

\section{Introduction}

The increasing digitalization of our society promises various benefits for private and professional life [1]. The healthcare sector in specific has been benefiting from improvements through digital technology and related innovations [2]-[4]. For example, the European commission's report on the impact of an interoperable electronic health record system concludes that even if its implementation takes a long time (six to eleven years), the benefits are manifold and substantial (e.g., improved compliance with clinical guidelines and better patient safety and reduced clinical risk, such as technical mistakes due to information availability) [5], [6]. However, the benefits of digital health concepts also come with challenges, rendering research in the domain of digital health-relevant and important [7]. Against this background, information system (IS) research can play a key role in investigating the design of such systems as well as in exploring phenomena related to their use, management, and impact [1], [8].

Accordingly, this paper has two main objectives. Firstly, we want to demonstrate the potential of the belief-action-outcome (BAO) framework of Melville [9] to structure and guide digital health research. The extensive framework includes variables at the macroand micro-level connecting social and organizational context with belief, action, and outcome formation. It links beliefs, actions, and outcomes of individual, organizational, and societal actors and is therefore well suited to analyze the impact of digital health. The system gives an extensive way to deal with analyzing the role of IS in empowering and changing feasible practices

Secondly, by applying the BAO framework to analyze current literature on digital health in IS research, we aim to identify research directions and to uncover research gaps to guide researchers to fill these gaps [9]. Given the connections laid out in the BAO structure, we build up a concept matrix that enables us to methodically orchestrate and integrate prior research, identify research foci [10], [11], and formulate directions for future research.

In order to achieve our objectives, the paper proceeds as follows. We begin by summarizing the current directions and research areas of digital health. Subsequently, we are conceptualizing the gap the BAO framework fills within our understanding of how IS impact healthcare. Next, we present the conceptual bases on which BAO was developed and the BAO framework itself. Following, we conceptualize how the framework can be adapted to fit the new context of digital health. We demonstrate the framework's value by applying it to recent research on health in the top- 
ranked IS journals. Based on our analysis, we elicit future research directions and questions.

\section{Health in Information System Research}

The research area of health in information system research is interdisciplinary and located at an intersection between societies, organizations, and consumers [7]. In general, the term "digital health" refers to some form of information technology or systems, which is applied in the context of health, such as in health institutions or for health management [12]. The term digital health has many definitions in scientific practice and can generally be described as the use of information and communication technologies to monitor and improve patient health and well-being [13]. Sub-categories of digital health are eHealth and mHealth. They particularly describe the form of technology use in health concepts. eHealth is an umbrella term for all digital technologies and applications used for patient care, such as electronic health records or hospital information systems [14]. In contrast, the term mHealth is derived from 'mobile' and addresses mobile devices, such as smartphones, tablets, or smartwatches, for health-related porpuses [15].

Overall, digital health research can be seen as an advancement of IS theory and practice [7]. Previous research has provided insights into the thematic progress of this research stream. Current literature reviews aim to provide an overview of the previous research by addressing digital health often with specific foci. The review articles reveal that the authors limit themselves to the study of IS specific clinical pictures such as mental disorders [16] or the use in certain geographical regions such as developing countries [17]. Besides, particular challenges such as data protection concerns and privacy connected with certain applications are examined [18]. Those current literature reviews that are not limited to specific niches but consider digital health as a broader field of research show limitations in the search terms used or the journals considered. In the methodical approaches of the existing literature reviews, either search terms were used to investigate eHealth [19] or mHealth [18], but not both components together, which limits the overall research agenda. For example, the study of Koffi et al. [18]limits the investigation area to mHealth in combination with privacy. This approach categorically excludes papers referring to terms such as eHealth or digital health and makes the consideration of privacy a necessary prerequisite. This seems to be insufficient, especially against the background of the manifold ways of defining digital health. In addition to the aforementioned content restrictions, all literature reviews known to us are limited in the selection of the journals examined. For example, Cohen et al. [17] or Hur et al. [20] search in various databases including Google Scholar, which does not consider the quality of outlet publication. Our research did not identify any literature review that exclusively analyzes the contributions of the high quality IS journals such as the AIS basket of eight and could, therefore, derive insights relevant for the future IS research agenda.

\section{The Belief-Action-Outcome Framework}

The BAO framework by Melville [9] provides a conceptual setting for "the development and adoption of information systems for environmental sustainability" [9] and the improvement of a promote understanding of context-related key issues. Hereby, the framework provides a structure that gives a farreaching way to deal with IS research on this topic by understanding human conduct as an interaction of affecting elements at the macro- and micro-level. Figure 1 visualizes the interplay of dimensions, where the vertical dimensions (macro- and micro-level) of the framework interact recursively with the horizontal dimension (belief, action, outcome).

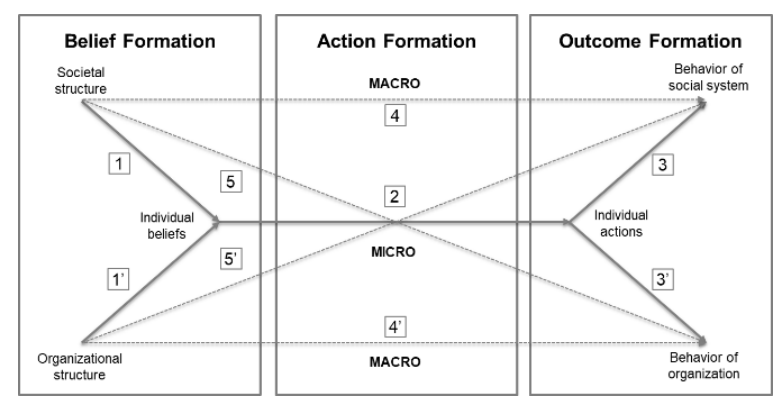

Figure 1. Belief-Action-Outcome framework (adopted by Melville [9])

The framework was originally developed and applied for the context of environmental sustainability [21]. However, we argue that the general nature of the framework enables the application in other contexts. The advantages of the BAO framework can be found especially in its ability to demonstrate the importance of information systems in changing environments, such as sustainability or health.

An essential aspect of the model is the distinction between the micro- and macro-levels, which considers the mediation and linkage of the individual with societal and organizational structure and the social system and organizations' behavior. The micro-level touches on individual beliefs and actions and the 
macro-level reflects social and organizational structures and their ecological and economic outcomes. The social structure refers to social and natural systems and includes individual and entrepreneurial actors [9]. Accordingly, the framework encompasses human behavior and the broader social and organizational contexts at the macro- and micro-levels. It considers social and organizational behaviors resulting from belief formation, action occurrence, and outcome evaluation. In digital health research, the vertical dimensions of the framework are distinguished between the societal, organizational, and individual perspectives. Research on a societal level addresses society's influence on health, e.g., cultural or institutional structures or national campaigns. At the organizational level, research focuses on the influence of organizations on health. This contains digital health suppliers, such as mHealth operators and healthcare providers, including hospitals. The research in this area concerns, for example, management strategies, organizational culture and structure, and disease management. On the individual level, research focuses on the individual's health attitudes, including patients with a specific disease and generally people operating with e.g., online health platforms.

The framework's horizontal dimension differentiates between the level of belief formation, action occurrence, and outcome assessment. Subsequently, the three dimensions are addressed in further detail and regarding the health context.

Belief - Belief formation is described by Melville [9] as "psychic states (beliefs, desires, attitudes, opportunities, etc.) about the natural environment." As we substitute the context, beliefs address the micro-level focus on the individual psychic state based on norms and values towards the health ecosystem. Individual belief formation about health is based on personal values, norms, and beliefs. As the health ecosystem conditions directly influence personally high valued subjects such as personal health, the health of family and peers, and individuals' beliefs that they can take measures to mitigate these conditions, beliefs are found encouraging pro-health behavior [23]. On the macro-level, belief formation within the societal and organizational structure is assessed. Individual beliefs are influenced by a variety of societal and organizational factors [9]. Normative patterns on the micro-level are thus influenced by societal factors (macro-micro: link 1), such as political discourse and family life, that form the belief about the state of the health ecosystem [24] as well as organizational structure (macro-micro: link 1'), representing how organizations allocate and coordinate labor, and use IS that create transparency regarding health aspects [25].

Action - The phase during which individual beliefs are converted into concrete actions is the action formation stage. On the micro-level (micro-micro: link 2 ), health-related actions, for instance, include the usage of mobile health applications [26], telemedicine systems [20], or interacting through online health communities [27]. On the macro-level, the BAO framework suggests that on the one hand, organizational structures influence the behavior of societies and organizations (macro-macro: link 4' and link 5') and on the other hand, societal structures directly influence health-related actions of societies and organizations (macro-macro: link 4 and link 5). Within the framework, an organization is defined as a group of homogenous agents, abstaining from individual human behavior [9]. On the macro-level, actions can include, for instance, the use of digital patient records [28], the reduction of healthcare spending through IS use [29], or the creation of social value [30].

Outcome - The effects of combined individual health actions on social (micro-macro: link 3) and organizational (micro-macro: link 3') behaviors are reflected in the outcome assessment. On the societal level, health outcomes refer to all influences on society and the entire health ecosystem, such as social health disparities, healthcare costs, and waste [9]. On the organizational level, organizational performance (e.g., reducing costs or increasing productivity) is the basis for outcome assessment, thus combining the importance of health outcomes and economic performance to transform the health ecosystem.

\section{Research Approach}

To review existing work on health in IS research, we conducted a systematic literature review process based on the approaches of Webster and Watson [11], van Brocke et al. [10], and Brendel et al. [31].

Table 1. Research approach phases

\begin{tabular}{c|l|l|l} 
& $\begin{array}{l}\text { Phase 1: } \\
\text { Gather Literature }\end{array}$ & $\begin{array}{l}\text { Phase 2: } \\
\text { Code Literature }\end{array}$ & $\begin{array}{l}\text { Phase 3: } \\
\text { Analyse Literature }\end{array}$ \\
\hline Input & $\begin{array}{l}\text { Published } \\
\text { journal articles }\end{array}$ & $\begin{array}{l}\text { Literature } \\
\text { database }\end{array}$ & $\begin{array}{l}\text { Coded literature } \\
\text { database }\end{array}$ \\
\hline Method & Literature search & Coding & Analysis \\
\hline Steps & $\begin{array}{l}\text { Conduct search } \\
\text { and filter } \\
\text { literature }\end{array}$ & $\begin{array}{l}\text { Define } \\
\text { dimensions }+ \\
\text { code literature }\end{array}$ & $\begin{array}{l}\text { Interpret coded } \\
\text { literature }\end{array}$ \\
\hline Results & $\begin{array}{l}\text { literature } \\
\text { database }\end{array}$ & $\begin{array}{l}\text { Coded literature } \\
\text { database }\end{array}$ & $\begin{array}{l}\text { Derive research } \\
\text { questions }\end{array}$
\end{tabular}

Our research approach is threefold (see Table 1). Firstly, the digital health publications from IS outlets are gathered. Secondly, the relevant literature is 
analyzed by coding along the dimensions of the BAO framework. Thirdly, the coded database is analyzed and discussed to identify research gaps and opportunities.

\section{Phase 1: Gather Literature}

During the first phase, we gathered literature to develop a digital health literature database in highquality IS research. The publications include all studies that deal with physical or mental health, focus on health-related artifacts, such as electronic health records, or set the primary focus on the healthcare context. We excluded all kinds of meta-analysis, literature reviews, or research framework publications to focus on empirical research with practical contributions. Furthermore, we limited our database to publications from the AIS basket of eight to ensure that our sample includes publications with high-level impact and rigor [32]. For the search, we applied the following search query:

(health*) OR (mhealth*) OR (m-health*) OR (ehealth*) OR (e-health*)

The literature search was conducted in May 2020 via the databases Taylor and Francis (EJIS), ScienceDirect (JSIS), SAGE (JIT), and EbscoHost (others). All articles were filtered via a two-step process. The articles were selected by title, keywords, and abstract. Afterward, they were reviewed regarding their fit for the research database, following the previously defined criteria (i.e., empirical research in digital health). We gathered a total of 47 publications to form our research database. The results of the literature search are documented in Table 2.

Table 2. Overall literature search results

\begin{tabular}{|l|ccc|}
\hline Journals & Total & Abstract / Title & Final \\
\hline ISR & 33 & 20 & 6 \\
MISQ & 41 & 35 & 16 \\
JMIS & 23 & 14 & 5 \\
JAIS & 28 & 18 & 8 \\
JIT & 55 & 9 & 2 \\
ISJ & 23 & 16 & 6 \\
JSIS & 45 & 4 & 0 \\
EJIS & 81 & 10 & 3 \\
\hline \multicolumn{5}{r}{ Total } & $\mathbf{1 1 6}$ & $\mathbf{4 6}$ \\
\hline
\end{tabular}

\section{Phase 2: Code Literature}

To generate insight into the selected database, we structured the literature along with the different levels and stages of the BAO framework to construct a concept matrix. Three authors coded the literature independently and discussed the results to reach a common understanding. All publications from the database were selected to fit at least one characteristic of each dimension.

\section{Phase 3: Analyse Literature}

To analyze the coded literature, we conducted a table for each level of the BAO dimension. We synthesized and interpreted the results of the identified studies. This phase is essential for a literature review to identify directions for future research by formulating research questions [11]. Since the microand macro-levels show the most distinct differences in the literature database, the results are presented for these levels.

\section{Results}

We identified 46 relevant papers that we further analyzed according to the attributes and links of the BAO framework through the literature review. Our review finds a significant differentiation between micro-level studies (18 studies), that include the micro-micro action link 2 and the micro-macro outcome links 3 and 3' and macro-level studies (28 studies) that include macro-micro links 1 and 1 ' as well as the macro-macro links 4, 5, 4' and 5'. Furthermore, most studies examine the action formation (40 studies, 17 on micro-level and 23 on macro-level), while fewer but equivalent studies focus on belief formation (30 studies, 4 on micro-level and 26 on macro-level) and outcome assessment (30 studies, 9 on micro-level and 21 on macro-level). Additionally, we unambiguously assigned the studies by research focus, differentiating between design studies (19 studies, 5 on micro-level and 14 on macrolevel) and behavior studies (27 studies, 13 on microlevel and 14 on macro-level).In the following, we provide a more in-depth evaluation of the studies, separated by micro-level studies (Table 3 ) and macrolevel studies (Table 4)

\subsection{Micro-level Studies}

Based on Table 3, we note that most micro-level studies address the individual level in combination with the influence of either the society level (four studies) or the organizational level (nine studies). However, four studies are restricted to the individual level. Regarding the formation level, the appropriation of studies is focused on the action formation (17 studies), while outcome assessment (nine studies) and belief formation (four studies) are seldomly addressed. Concerning the research focus, most studies consider behavioral aspects (13 studies), while only five studies address the design.

Some studies focused on action formation and the role of the individual. Such research promotes the design of online systems to enhance user engagement [27], [33], or analyzes the behavior of users, e.g., 
information use behavior of people with disabilities [34], communication in virtual health communities [35], or disease management behavior [36]. However, several studies combine such individual action with the belief formation encouraged by organizations. Online health communities and online health platform interventions thereby offer such research possibilities by user engagement and activity [20], [37], [38]. Similarly, Venkatesh et al. [39] address eHealth kiosks in India to raise individual awareness of infant care and change individual behavior.

Table 3. Concept matrix - micro-level studies

\begin{tabular}{|c|c|c|c|c|c|c|c|c|c|c|}
\hline \multirow[b]{2}{*}{ Paper } & \multirow[b]{2}{*}{ Outlet } & \multicolumn{2}{|c|}{ Focus } & \multicolumn{3}{|c|}{ Formation } & \multicolumn{3}{|c|}{ Level } & \multirow[b]{2}{*}{$\begin{array}{l}\text { BAO } \\
\text { Link }\end{array}$} \\
\hline & & $\begin{array}{l}\frac{5}{0} \\
\text { कू } \\
0\end{array}$ & 高 & 㐫 & 을 & 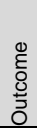 & $\begin{array}{l}\frac{7}{0} \\
\frac{0}{0} \\
0 \\
0\end{array}$ & 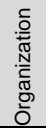 & 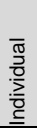 & \\
\hline [20] Hur et al. 2019 & EJIS & & $\frac{\vec{X}}{X}$ & $\mathrm{X}$ & $\bar{x}$ & & & $x$ & $\bar{x}$ & $1^{\prime}+2$ \\
\hline 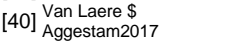 & EJIS & & $x$ & & $x$ & $x$ & & $x$ & $x$ & $2+3$ \\
\hline $\begin{array}{l}\text { [37] Zhang et al. } 2019 \\
\text { [41] James et al. } 2019 \\
\text { [27] Hansen et al. } 2019\end{array}$ & $\begin{array}{l}\text { EJIS } \\
\text { ISJ } \\
\text { ISJ }\end{array}$ & $x$ & $\begin{array}{l}x \\
x\end{array}$ & $x$ & $\begin{array}{l}X \\
X \\
x\end{array}$ & $x$ & & $\begin{array}{l}X \\
X\end{array}$ & $\begin{array}{l}x \\
x \\
x\end{array}$ & $\begin{array}{c}1 '+2 \\
2+3 \\
2\end{array}$ \\
\hline $\begin{array}{l}\text { [27] Hansen et al. } 2019 \\
\text { [42] Bernadi \& Exworthy } \\
2020\end{array}$ & ISJ & & $x$ & & $x$ & $x$ & & $x$ & $x$ & $\begin{array}{c}2 \\
2+3\end{array}$ \\
\hline $\begin{array}{l}\text { [33] Hao et al. } 2018 \\
\text { [43] Khurana et al. } 2017\end{array}$ & $\begin{array}{l}\text { ISR } \\
\text { ISR }\end{array}$ & $x$ & $x$ & & $\begin{array}{l}x \\
x\end{array}$ & $\mathrm{X}$ & $\mathrm{x}$ & & $\begin{array}{l}x \\
x\end{array}$ & $\begin{array}{c}2 \\
2+3\end{array}$ \\
\hline $\begin{array}{l}\text { [35] Kordzadeh and Warren } \\
2017\end{array}$ & JAIS & & $x$ & & $x$ & & & & $x$ & 2 \\
\hline $\begin{array}{l}\text { [34] Liang et al. } 2017 \\
\text { [38] Yan \& Tan } 2017\end{array}$ & $\begin{array}{l}\text { JAIS } \\
\text { JMIS }\end{array}$ & & $\begin{array}{l}X \\
X\end{array}$ & $x$ & $\begin{array}{l}x \\
X\end{array}$ & & & $\mathrm{X}$ & $\begin{array}{l}x \\
x\end{array}$ & $\begin{array}{c}2 \\
1^{\prime}+2\end{array}$ \\
\hline [44] Baird et al. 2017 & JMIS & $\mathrm{x}$ & & & $x$ & $x$ & & $x$ & $x$ & $2+3$ \\
\hline [45] Venkatesh et al. 2016 & MISQ & & $\mathrm{x}$ & $\mathrm{x}$ & $\mathrm{x}$ & & & $\mathrm{x}$ & $\mathrm{x}$ & $1^{\prime}+2$ \\
\hline [46] Huang et al. 2019 & $A I C$ & & $x$ & & $\mathrm{x}$ & $x$ & $\mathrm{x}$ & & $\mathrm{x}$ & $2+3$ \\
\hline [47] Liu et al. 2020 & MISQ & $\mathrm{x}$ & & & $x$ & $x$ & $x$ & & $x$ & $2+3$ \\
\hline [36] Son et al. 2020 & MISQ & $x$ & & & $x$ & & & & $x$ & 2 \\
\hline [48] Bao et al. 2020 & & & $x$ & & $\mathrm{x}$ & $x$ & & $\mathrm{x}$ & $\mathrm{x}$ & $2+3$ \\
\hline [49] Venkatesh & MISQ & & 入 & & $\mathrm{x}$ & $\mathrm{x}$ & $\mathrm{x}$ & & $\mathrm{x}$ & $2+3$ \\
\hline Total $(n=18)$ & & 5 & 13 & 4 & 17 & 9 & 4 & 9 & 18 & \\
\hline
\end{tabular}

While the beforementioned studies use an organizational study to form beliefs, our sample does not include a single study in which society aims to form individual health beliefs. Furthermore, action formation is also often combined with the outcome assessment. For example, van Laere and Aggestam [40] investigate the so-called champion user's behavior in health IS and its impact on collective social interaction. Bao et al. [48] investigate the engagement of people with chronic diseases in digital patient portals and its influence on the frequency of hospital and emergency visits, readmission risk, and length of stay. While these two studies are examples of how individual behavior and action influence an organizational outcome, Venkatesh et al. [49] develop a two-stage model that shows the impact of individual behavior on the village and hence the society in the context of eHealth kiosk. The societal outcome is also assessed by Liu et al. [47], who derive contribution to public health practices based on individual engagement with health content in social media platforms.

Overall, it is notable that studies on the micolevel show considerably limited interplay with the society level, while the interaction with specific organizations is well researched. Lastly, studies on the miro-level are limited in design focus. However, this is an important aspect, as the few existing studies emphasize.

\subsection{Macro-level Studies}

When looking at the distribution displayed in Table 4, we note an even distribution of studies regarding the focus on either design (14 studies) or behavior (14 studies). For the dimensions of formation, a similar even distribution is observed. Twenty-six studies consider belief formation, 23 studies address action formation and 21 studies on outcome assessment. Regarding the influence on either society or organizations, we note that most studies focus on organizational influence (20 studies), while only 14 studies assess influences on a societal level. Overall, nine studies connect to the mico-level. Seven studies connect the organizational and individual levels, while only two studies address the interplay of societal and micro-level.

In the context of aligning digital health and organizational structure, most studies consider the design aspects that form outcomes in the behavior of organizations. Overall, eight studies can be allotted to research that assesses the design focus on outcome formation in an organizational context. Three different lines of focus can be identified in this research. Firstly, some studies examine general conditions and challenges in the implementation process of IS in the health context, such as withholding of information and differing stakeholder interests [50], [51]. Subsequently, the second research focus pinpoints tangible scopes of the application of IS systems in the context of health [52], [44]. Lin et al. [28] use the data generated through electronic health records to derive health risk assessments for patients that can consider multiple possible adverse health events. Finally, the third line of research discloses the general effects of IS's implementation in the health context. Pinsonneault et al. [8] examine the direct and indirect effects of health information technology on the quality of care as a central dimension of the entire health sector.

Research that can be allotted to the parameters "behavior," "outcome," and "organization," commonly focus on the effects of the usage of electronic health records. The effects that are assessed in this context are rather diverse. While Ayabakan et al.[53] point out that waste can be reduced by avoiding the necessity of duplicate testing, Romanow et al. [54] evaluate how computerized order entry can benefit patient care teams in their coordination of patient care 
and to inform patients about their care. They find that the use of computerized order entry leads ultimately to improved patient satisfaction. Baird et al. [44] evaluated electronic health record assimilation in 10 small physician practices in a similar vein.

Table 4. Concept matrix - Macro-level studies

\begin{tabular}{|c|c|c|c|c|c|c|c|c|c|c|}
\hline \multirow[b]{2}{*}{ Paper } & \multirow[b]{2}{*}{ Outlet } & \multicolumn{2}{|c|}{ Focus } & \multicolumn{3}{|c|}{ Formation } & \multicolumn{3}{|c|}{ Level } & \multirow[b]{2}{*}{$\begin{array}{l}\text { BAO } \\
\text { Link }\end{array}$} \\
\hline & & $\begin{array}{l}\text {.5 } \\
\text { வ } \\
0\end{array}$ & 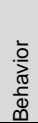 & $\begin{array}{l}\stackrel{\bar{\Phi}}{\bar{\Phi}} \\
\varnothing\end{array}$ & 은 & 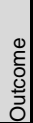 & $\begin{array}{l}\overrightarrow{0} \\
\frac{0}{0} \\
\text { क }\end{array}$ & 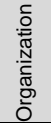 & 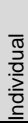 & \\
\hline [26] Fox \& Connolly 2018 & ISJ & $\bar{X}$ & & $\mathrm{X}$ & & & & $\bar{X}$ & & $1^{\prime}$ \\
\hline [55] Mettler 2018 & ISJ & $\bar{x}$ & & & $\mathrm{X}$ & & & $\bar{X}$ & & 4 \\
\hline [56] Murungi et al. 2019 & ISJ & & $\bar{X}$ & & $\bar{x}$ & & & $\bar{X}$ & & 4 \\
\hline [57] Demirezen et al. 2016 & ISR & & $\bar{X}$ & $\mathrm{X}$ & $\mathrm{X}$ & $\mathrm{x}$ & & $\bar{X}$ & $\mathrm{X}$ & $3^{\prime \prime}+4^{\prime}$ \\
\hline [29] Adjerid et al. 2018 & ISR & $\bar{X}$ & & $\mathrm{X}$ & $\mathrm{X}$ & $\mathrm{X}$ & $\mathrm{X}$ & $\bar{X}$ & & $4+5$ \\
\hline [28] Lin et al. 2019 & ISR & $\bar{X}$ & & $\mathrm{X}$ & $\mathrm{X}$ & $\mathrm{x}$ & $\mathrm{X}$ & $\bar{X}$ & & $4^{\prime}+5^{\prime}$ \\
\hline [1] Hansen \& Barody & ISR & & $\mathrm{X}$ & $\mathrm{x}$ & $x$ & $\mathrm{x}$ & $\mathrm{X}$ & $\mathrm{X}$ & & $4^{\prime}+5^{\prime}$ \\
\hline [51] Pouloudi et al. 2016 & JAIS & $\mathrm{X}$ & & $\mathrm{X}$ & $\bar{x}$ & $\bar{x}$ & & $\bar{X}$ & & $\overline{4}$ \\
\hline [58] Bernardi 2017 & JAIS & & $\bar{X}$ & $\mathrm{X}$ & $\mathrm{x}$ & $\mathrm{x}$ & $\mathrm{X}$ & $\bar{x}$ & & $4+5$ \\
\hline [59] Dadgar \& Joshi 2018 & JAIS & $\bar{X}$ & & $\mathrm{X}$ & & & & $\bar{X}$ & $\bar{x}$ & $1^{\prime}$ \\
\hline [15] Chen et al. 2019 & JAIS & & $\bar{X}$ & $\mathrm{X}$ & & & $\mathrm{X}$ & & $\mathrm{X}$ & 1 \\
\hline$[60]_{2019}^{\text {Dissanayake et al. }}$ & JAIS & $\mathrm{x}$ & & $x$ & & & & $x$ & & $1^{\prime}$ \\
\hline [50] Yaraghi et al. 2019 & JAIS & $\mathrm{X}$ & & $\mathrm{X}$ & & & & $\bar{X}$ & $\bar{x}$ & 1' \\
\hline [61] Findikoglu et al. 2016 & JIT & $\bar{x}$ & & $\bar{x}$ & $\bar{X}$ & $\bar{X}$ & $\bar{x}$ & & & 5 \\
\hline [62] Klecun et al. 2019 & JIT & $\mathrm{X}$ & & $\mathrm{X}$ & $\mathrm{X}$ & $\mathrm{x}$ & $\mathrm{X}$ & $\bar{X}$ & & $4+5$ \\
\hline [8] Pinsonneault 2017 & JMIS & $x$ & & $\mathrm{X}$ & $\mathrm{x}$ & $\mathrm{x}$ & & $\mathrm{X}$ & & $4^{\prime}$ \\
\hline [63] Chen et al. 2019 & JMIS & & $\bar{X}$ & $\mathrm{X}$ & $\mathrm{X}$ & $\mathrm{x}$ & $\mathrm{X}$ & & & 4 \\
\hline [64] Danish et al. 2019 & JMIS & & $\bar{X}$ & $\mathrm{X}$ & $\mathrm{X}$ & $\mathrm{X}$ & & $\bar{X}$ & & 4' \\
\hline [30] Goh et al. 2016 & MISQ & & $\mathrm{X}$ & $\mathrm{X}$ & $\mathrm{X}$ & $\mathrm{x}$ & $\mathrm{X}$ & & & 4 \\
\hline [65] Kartik et al. 2016 & MISQ & & $\mathrm{X}$ & $\mathrm{X}$ & $\mathrm{X}$ & $\mathrm{x}$ & $\mathrm{X}$ & & & 4 \\
\hline [52] Lin et al. 2017 & MISQ & $\mathrm{X}$ & & $\mathrm{X}$ & $\mathrm{X}$ & $\mathrm{X}$ & & $\mathrm{X}$ & $\mathrm{X}$ & 4 \\
\hline [53] Ayabakan et al. 2017 & MISQ & & $\mathrm{X}$ & $\mathrm{X}$ & $\mathrm{X}$ & $\mathrm{x}$ & & $\mathrm{X}$ & & 4' \\
\hline [54] Romanow et al. 2018 & MISQ & & $\bar{X}$ & $\mathrm{X}$ & $\mathrm{x}$ & $\mathrm{x}$ & & $\bar{x}$ & $x$ & $3^{\prime \prime}+4^{\prime}$ \\
\hline [66] Bernardi et al. 2019 & MISQ & $\mathrm{X}$ & & $\mathrm{X}$ & $\mathrm{x}$ & $\mathrm{x}$ & $x$ & & & 4 \\
\hline [67] Essén et al. 2019 & MISQ & & $\bar{X}$ & $\mathrm{X}$ & $\mathrm{X}$ & $\mathrm{X}$ & $\mathrm{X}$ & $\bar{X}$ & & 5' \\
\hline [68] Zhang et al. 2020 & MISQ & $\mathrm{X}$ & & $\mathrm{X}$ & $\mathrm{X}$ & $\mathrm{X}$ & $\mathrm{X}$ & & $\mathrm{X}$ & $3+4$ \\
\hline [69] Liu et al. 2020 & MISQ & & $\bar{X}$ & $\mathrm{X}$ & $\mathrm{X}$ & $\mathrm{x}$ & & $\bar{X}$ & $\bar{x}$ & $3^{\prime \prime}+4^{\prime}$ \\
\hline [70] Thompson et al. 2020 & MISQ & & $\mathrm{X}$ & $\mathrm{X}$ & $\mathrm{X}$ & $\mathrm{x}$ & $\mathrm{X}$ & & & 4 \\
\hline Total $(n=28)$ & & $\overline{14}$ & $\overline{14}$ & 26 & 23 & 21 & 14 & 20 & 9 & \\
\hline
\end{tabular}

Within the macro-level, the research aligning digital health and societal structure is primarily focused on the influence on the social system's behavior. Chen et al. [63] and Goh et al. [32], conduct research regarding the effects of online health communities. While Chen et al. [63] emphasize the effect of online communities in the provision of social support, Goh et al. [30] find that online communities create social value by overcoming rural-urban health disparities. Contrary to these studies, Thompson et al. [70] focus their research on the economic effects through IT use in healthcare besides patient health outcomes and find that healthcare costs can be reduced through the use of IT in the context of chronic disease management. Bernardi et al. [66] took a different viewpoint and uncovered the need for disruption of dysfunctional health information system routines embedded in institutions or deinstitutionalization for health IS to unfold their full potential in improving citizens' health in low and middle-income countries.

Additional research at the macro-level focuses on outcomes at the organizational as well as the societal level. Research in this area is primarily concerned with the implementation of electronic health records. While Adjerid et al. [29] argue that health records reduce medicare spending and frictions in information sharing, Klecun et al. [62] pinpoint that forcing the introduction of such in a top-down approach thus exercising institutional pressure on medical professionals will yield negative outcomes rendering the benefits. In line with the research of Klecun et al. [62], Findikoglu et al. [61] find that the goal alignment between governments and medical professionals is critical for the success of electronic health records enabled transformations of health care services. Their research is focused on the link between societal beliefs and organizational outcomes. They conclude that healthcare goals on a societal level need to be linked to the system usage on an individual level to contribute to these goals; otherwise, they will lead to unintended negative health outcomes. This can only be done through the organizational context in which societal goals are embedded.

In contrast to the research above, Chen et al. [15] research the influence of societal belief regarding health on the individuals' beliefs as they focus on uncovering what channels individuals prefer in the context of mHealth use to deduce insights for the design of m-health offers. Notably, most studies on the societal level take a country-specific perspective, as health ecosystems tend to differ strongly due to varying economic and political backgrounds.

\section{Directions for Future Research}

Our study aims at examining the current focus of health in IS research. In our literature review, we identified 46 relevant papers that were analyzed using the BAO framework. Our review reveals a lack of studies that analyze the interdependencies of the micro- and macro-level and design of health IS. In the following, we propose directions for future research based on our findings.

All studies analyzed addressed the outcome level only in combination with some links on the action level. It is noticeable that the papers mostly analyzed some form of action, e.g., champion behavior and its impact on the organization [40]. However, we could not identify a single study that solely focused on the outcomes. For example, this could be addressed by an examination of various outcome types, such as social phenomena that drive adoption of health IS, or impact on society of mHealth applications in place. The publications of, Hansen [1], Klecun et al. [62], and Adjerid et al. [29] for example, cover all formation stages but leave out the consideration of the role of the individual. Therefore, we call future research to work 
on outcome investigations that isolate BAO link 3 and 3'. To summarize, we propose the following research question:

RQ 1: How can organizational and societal outcomes result from the use of health IS?

Our results have identified the organizational level as the dominant focus also in combination with the micro-level. In total, nine studies at the micro-level and 20 studies at the macro-level address the organizational level. However, it is noticeable that only a few studies examine the organizational level by setting the research focus on an IS design. Notably, at the interaction with the micro-level, there is a lack of studies. This raises the question of why the design focus is underrepresented in this context. Research in this area could examine specific design elements in mHealth apps, such as gamification features like rewards on the individual health course. Therefore, design studies are needed that address the design of an organization's health IS and analyze how this design influences the individual.

RQ2: What design approaches are effective for developing health IS that influence individual beliefs and actions?

When looking at the societal perspective, research is commonly showing the positive impact of IS on health outcomes, especially in low- and middle-income countries. Moreover, researchers agree upon the necessity to align institutional and organizational goals [62]. However, research addressing the necessary structures to overcome such obstacles is lacking. For instance, the involvement of medical professionals in government institutions or possible direct communication channels between political decisionmakers and medical professionals is not addressed in research yet. Thus, we propose the following research question:

RQ3: What institutional structures foster the adoption of digital health systems at the organizational level?

On the micro-level, we only identified four studies addressing belief formation. In comparison, we identified 26 studies on the macro-level. Our results indicate a need for further research in the field of belief formation, which also addresses the individual action formation at the micro-level. Until now, belief formation has solely focused on organizational and societal levels, largely ignoring the impact on the individual. However, such research is important because the macro perspective can influence individual action through belief formation. For example, Fox et al. [26] have shown how mHealth applications can reduce costs for the healthcare system on the one hand and encourage patients to take a proactive approach on the other. Likewise, Dadgar et al. [59] investigate how the design of digital health applications influences the self-management of diabetes patients.

RQ4: Which opportunities and solutions can digital health offer to influence belief formation that affects individual action formation positively? In our research, we were not able to identify any multilevel studies that investigated micro-level and macrolevel in the categories of belief formation, action, and outcome assessment. As the considered studies do not address this complex interplay at full range, we encourage future research to employ more research in this area to address the complexity of information systems in health care entirely is not fully covered. If this research gap is not closed in the future, IS research will not meet its aspirations for interdisciplinarity.

RQ5: How do multi-level interactions between macro- and micro-levels impact belief formation, action formation, and outcome assessment?

Our research reveals that the influence of institutional, societal, and organizational structures on individual health-related beliefs is strongly underrepresented in current research and should thus receive more attention, as beliefs are a powerful instrument in the process of long-term sustainable changes. Thus, we propose the following research question:

RQ6: How do societal, institutional, and organizational structures influence individual actors' health-related behaviors and usage of digital health systems?

\section{Concluding Remarks}

The goal of this study was to analyze the current health agenda in IS research. Our study extended previous literature reviews in the health context by applying a structural framework to the research body of high raked studies. Furthermore, we contribute to research by showing that the BAO framework can be a relevant lens to shape and conduct digital health research. Lastly, our study is not free of limitations. Our results are limited to the selected outlets' scopes and keywords that we included in the search string. Future research should elaborate on our future research directions and research questions, and also apply for a broader scope of health research in IS conferences, other journals, and in interdisciplinary research outlets.

\section{References}

[1] S. Hansen and A. J. Baroody, "Electronic Health Records and the Logics of Care: Complementarity and Conflict in the U.S. Healthcare System," Information Systems Research, vol. 31, no. 1, Mar. 
2020, pp. 57-75, doi: 10.1287/isre.2019.0875.

[2] L. Gastaldi and M. Corso, "Smart Healthcare Digitalization: Using ICT to Effectively Balance Exploration and Exploitation within Hospitals," International Journal of Engineering Business Management, vol. 4, Jan. 2012, p. 9, doi: $10.5772 / 51643$.

[3] Romanow, Cho, and Straub, "Riding the Wave: Past Trends and Future Directions for Health IT Research," MIS Quarterly, vol. 36, no. 3, 2018, p. iii.

[4] S. Singhal, B. Latko, and C. P. Martin, "The future of healthcare : Finding the opportunities that lie beneath the uncertainty," 2018.

[5] European Commission, "The Socio-Economic Impact of Interoperable Electronic Health Record (EHR) and ePrescribing Systems in Europe and Beyond," EHR Impact, no. October, 2009, p. 44.

[6] M. Shaw and B. Stahl, "On Quality and Communication: The Relevance of Critical Theory to Health Informatics," Journal of the Association for Information Systems, vol. 12, no. 3, 2011, pp. 255273, doi: 10.17705/1jais.00261.

[7] A. Baird, C. Angst, and E. Oborn, "Health Information Technology," in MIS Quarterly Research Contributions, 2018.

[8] A. Pinsonneault, S. Addas, C. Qian, V. Dakshinamoorthy, and R. Tamblyn, "Integrated Health Information Technology and the Quality of Patient Care: A Natural Experiment," Journal of Management Information Systems, vol. 34, no. 2, 2017, pp. 457-486.

[9] N. P. Melville, "Information Systems Innovation for Environmental Sustainability," MIS Quarterly, vol. 34, no. 1, 2010, pp. 1-21.

[10] J. vom Brocke et al., "Reconstructing the Giant: On the Importance of Rigour in Documenting the Literature Search Process," ECIS 2009 Proceedings, vol. 161, 2009.

[11] J. Webster and R. T. Watson, "Analyzing the Past to Prepare for the Future: Writing a Literature Review.," MIS Quarterly, vol. 26, no. 2, 2002, pp. xiii-xxiii, doi: 10.1.1.104.6570.

[12] B. Meskó, Z. Drobni, É. Bényei, B. Gergely, and Z. Györffy, "Digital health is a cultural transformation of traditional healthcare," mHealth, vol. 3, 2017, pp. 38-38, doi: 10.21037/mhealth.2017.08.07.

[13] G. E. Iyawa, M. Herselman, and A. Botha, "Digital Health Innovation Ecosystems: From Systematic Literature Review to Conceptual Framework," Procedia Computer Science, vol. 100, 2016, pp. 244 252, doi: 10.1016/j.procs.2016.09.149.

[14] H. Kelley, M. Chiasson, A. Downey, and D. Pacaud, "The Clinical Impact of eHealth on the SelfManagement of Diabetes: A Double Adoption Perspective," Journal of the Association for Information Systems, vol. 12, no. 3, 2018, pp. 208234.

[15] L. Chen, A. Baird, and A. Rai, "Mobile health (Mhealth) channel preference: An integrated perspective of approach-avoidance beliefs and regulatory focus," Journal of the Association for
Information Systems, vol. 20, no. 12, 2019, pp. 1743 1773, doi: $10.17705 / 1$ jais.00584.

[16] F. Wahle and T. Kowatsch, "Towards the design of evidence-based mental health information systems: A preliminary literature review," in 35th International Conference on Information Systems, 2014, pp. 1-12.

[17] J. Cohen, E. Coleman, and L. Abrahams, "Use and impacts of e-health within community health facilities in developing countries: A systematic literature review," 2015.

[18] B. J. B. Koffi, A. Yazdanmehr, and R. K. Mahapatra, "Mobile health privacy concerns - A systematic review," Americas Conference on Information Systems 2018: Digital Disruption, AMCIS 2018, 2018, pp. 1-10.

[19] E. V. Wilson, W. Wang, and S. D. Sheetz, "Underpinning a guiding theory of patient-centered ehealth," Communications of the Association for Information Systems, vol. 34, no. 1, 2014, pp. 337350, doi: $10.17705 / 1$ cais.03416.

[20] I. Hur, K. C. Cousins, and B. C. Stahl, “A critical perspective of engagement in online health communities," European Journal of Information Systems, vol. 28, no. 5, Sep. 2019, pp. 523-548, doi: 10.1080/0960085X.2019.1620477.

[21] F. Ter Chian Tan and R. Vasa, "Toward a Social Media Usage Policy," ACIS 2011 Proceedings, 2011.

[22] N. P. Melville, "Information Systems Innovation for Environmental Sustainability," MIS Quarterly, vol. 34, no. 1, 2010, pp. 1-21.

[23] L. Steg, L. Dreijerink, and W. Abrahamse, "Factors influencing the acceptability of energy policies: A test of VBN theory," Journal of Environmental Psychology, vol. 25, no. 4, Dec. 2005, pp. 415-425, doi: 10.1016/j.jenvp.2005.08.003.

[24] R. Lülfs and R. Hahn, "Corporate Greening beyond Formal Programs, Initiatives, and Systems: A Conceptual Model for Voluntary Pro-environmental Behavior of Employees," European Management Review, vol. 10, no. 2, Jun. 2013, pp. 83-98, doi: 10.1111/emre. 12008 .

[25] H. Mintzberg, "The Structuring of Organizations," in Readings in Strategic Management, Macmillan Education UK, 1989, pp. 322-352.

[26] G. Fox and R. Connolly, "Mobile health technology adoption across generations: Narrowing the digital divide," in Information Systems Journal, 2018, vol. 28, no. 6, pp. 995-1019.

[27] S. W. Hansen, J. L. Gogan, R. J. Baxter, and M. J. Garfield, "Informed collaboration in health care: An embedded-cases study in geriatric telepsychiatry," Information Systems Journal, vol. 29, no. 2, Mar. 2019, pp. 514-547, doi: 10.1111/isj.12218.

[28] Y.-K. Lin, M. Lin, and H. Chen, "Do Electronic Health Records Affect Quality of Care? Evidence from the HITECH Act," Information Systems Research, vol. 30, no. 1, Mar. 2019, pp. 306-318, doi: 10.1287/isre.2018.0813.

[29] I. Adjerid, J. Adler-Milstein, and C. Angst, "Reducing medicare spending through electronic health information exchange: The role of incentives 
and exchange maturity," Information Systems Research, vol. 29, no. 2, 2018, pp. 341-361, doi: 10.1287/isre.2017.0745.

[30] J. M. Goh, G. G. Gao, and R. Agarwal, "The creation of social value: Can an online health community reduce rural-urban health disparities?," MIS Quarterly, vol. 40, no. 1, 2016, pp. 247-263, doi: 10.25300/MISQ/2016/40.1.11.

[31] A. B. Brendel, S. Trang, M. Marrone, and S. Lichtenberg, "What To Do for a Literature Review ? Synthesis of Literature Review Practices," Proceeding of Americas Conference on Information System, no. August, 2020, pp. 1-14.

[32] Y. Levy and T. J. Ellis, "A systems approach to conduct an effective literature review in support of information systems research," Informing Science, vol. 9, 2006, pp. 181-211, doi: 10.28945/479.

[33] H. Hao, R. Padman, B. Sun, and R. Telang, "Quantifying the Impact of Social Influence on the Information Technology Implementation Process by Physicians: A Hierarchical Bayesian Learning Approach," Information Systems Research, vol. 29, no. 1, Mar. 2018, pp. 25-41, doi: 10.1287/isre.2017.0746.

[34] H. Liang, Y. Xue, and Z. Zhang, "Understanding online health information use: The case of people with physical disabilities," Journal of the Association for Information Systems, vol. 18, no. 6, 2017, pp. 433-460, doi: 10.17705/1jais.00461.

[35] N. Kordzadeh and J. Warren, "Communicating Personal Health Information in Virtual Health Communities: An Integration of Privacy Calculus Model and Affective Commitment Communicating Personal Health Information in Virtual Health Communities: An Integration of Privacy Calculus Model an," Journal of the Association for Information Systems, vol. 18, no. 1, 2017, pp. 45-81.

[36] J. Son, P. Flatley Brennan, and S. Zhou, "A Data Analytics Framework for Smart Asthma Management Based on Remote Health Information Systems with Bluetooth-Enabled Personal Inhalers," MIS Quarterly, vol. 44, no. 1, 2020, pp. 285-303, doi: $10.25300 / \mathrm{misq} / 2020 / 15092$.

[37] X. Zhang, X. Guo, K. hung Lai, and W. Yi, "How does online interactional unfairness matter for patient-doctor relationship quality in online health consultation? The contingencies of professional seniority and disease severity," European Journal of Information Systems, vol. 28, no. 3, 2019, pp. 336354, doi: 10.1080/0960085X.2018.1547354.

[38] L. Yan and Y. Tan, "The Consensus Effect in Online Health-Care Communities," Journal of Management Information Systems, vol. 34, no. 1, 2017, pp. 11-39, doi: 10.1080/07421222.2017.1296742.

[39] V. Venkatesh, H. Bala, and V. Sambamurthy, "Implementation of an Information and Communication Technology in a Developing Country: A Multimethod Longitudinal Study in a Bank in India," Information Systems Research, vol. 27, no. 3, Sep. 2016, pp. 558-579, doi: 10.1287/isre.2016.0638.
[40] J. van Laere and L. Aggestam, "Understanding champion behaviour in a health-care information system development project - how multiple champions and champion behaviours build a coherent whole," European Journal of Information Systems, vol. 25, no. 1, Jan. 2016, pp. 47-63, doi: 10.1057/ejis.2015.5.

[41] T. L. James, J. K. Deane, and L. Wallace, "An application of goal content theory to examine how desired exercise outcomes impact fitness technology feature set selection," Information Systems Journal, vol. 29, no. 5, Sep. 2019, pp. 1010-1039, doi: 10.1111/isj.12233.

[42] R. Bernardi and M. Exworthy, "Clinical managers' identity at the crossroad of multiple institutional logics in it innovation: The case study of a health care organization in England," Information Systems Journal, vol. 30, no. 3, May 2020, pp. 566-595, doi: 10.1111/isj.12267.

[43] S. Khurana, L. Qiu, and S. Kumar, "When a Doctor Knows, It Shows: An Empirical Analysis of Doctors' Responses in a Q\&amp;A Forum of an Online Healthcare Portal," Information Systems Research, vol. 30, no. 3, Sep. 2019, pp. 872-891, doi: 10.1287/isre.2019.0836.

[44] A. Baird, E. Davidson, and L. Mathiassen, "Reflective Technology Assimilation: Facilitating Electronic Health Record Assimilation in Small Physician Practices," Journal of Management Information Systems, vol. 34, no. 3, 2017, pp. 664694, doi: 10.1080/07421222.2017.1373003.

[45] V. Venkatesh, A. Rai, T. A. Sykes, and R. Aljafari, "Combating infant mortality in Rural India: Evidence from a field study of Ehealth Kiosk implementations," MIS Quarterly, vol. 40, no. 2, 2016, pp. 353-380, doi: 10.25300/MISQ/2016/40.2.04.

[46] K. Y. Huang, I. S. Chengalur-Smith, and A. Pinsonneault, "Sharing is caring: Social support provision and companionship activities in healthcare virtual support communities1," MIS Quarterly, vol. 43, no. 2, 2019, pp. 395-423, doi: 10.25300/MISQ/2019/13225.

[47] X. Liu, B. Zhang, A. Susarlia, and R. Padman, "Go to You Tube and Call Me in the Morning: Use of Social Media for Chronic Conditions," MIS Quarterly, vol. 44, no. 1, 2020, pp. 257-283, doi: $10.25300 / \mathrm{misq} / 2020 / 15107$.

[48] C. Bao, I. R. Bardhan, H. Singh, B. A. Meyer, and K. Kirksey, "Patient-Provider Engagement and its Impact on Health Outcomes: A Longitudinal Study of Patient Portal Use," MIS Quarterly, vol. 44, no. 2, 2020, pp. 699-723, doi: 10.25300/MISQ/2020/14180.

[49] V. Venkatesh, T. A. Sykes, and X. Zhang, "ICT for Development in Rural India: A Longitudinal Study of Women's Health Outcomes," MIS Quarterly, vol. 44, 2020, pp. 605-629, doi: 10.25300/MISQ/2020/12342.

[50] N. Yaraghi, R. D. Gopal, and R. Ramesh, "Doctors' orders or patients' preferences? Examining the role of 
physicians in patients' privacy decisions on health information exchange platforms," Journal of the Association for Information Systems, vol. 20, no. 7, 2019, pp. 928-952, doi: 10.17705/1 jais.00557.

[51] N. Pouloudi, W. Currie, and E. A. Whitley, "Entangled stakeholder roles and perceptions in health information systems: A longitudinal study of the U.K. NHS N3 Network," Journal of the

Association for Information Systems, vol. 17, no. 2, 2016, pp. 107-161, doi: 10.17705/1jais.00421.

[52] Y. K. Lin, H. Chen, R. A. Brown, S. H. Li, and H. J. Yang, "Healthcare predictive analytics for risk profiling in chronic care: A Bayesian multitask learning approach," MIS Quarterly, vol. 41, no. 2, 2017, pp. 473-495, doi: 10.25300/MISQ/2017/41.2.07.

[53] S. Ayabakan, I. Bardhan, Z. (Eric) Zheng, and K. Kirksey, "The Impact of Health Information Sharing on Duplicate Testing," MIS Quarterly, vol. 41, 2017, pp. 1083-1103.

[54] D. Romanow, A. Rai, and M. Keil, "Cpoe-enabled coordination: Appropriation for deep structure use and impacts on patient outcomes," MIS Quarterly, vol. 42, no. 1, 2018, pp. 189-212, doi: 10.25300/MISQ/2018/13275.

[55] T. Mettler, "Contextualizing a professional social network for health care: Experiences from an action design research study," Information Systems Journal, vol. 28 , no. 4, Jul. 2018, pp. 684-707, doi: 10.1111/isj.12154.

[56] D. Murungi, M. Wiener, and M. Marabelli, "Control and emotions: Understanding the dynamics of controllee behaviours in a health care information systems project," Information Systems Journal, vol. 29, no. 5, Sep. 2019, pp. 1058-1082, doi: 10.1111/isj.12235.

[57] E. M. Demirezen, S. Kumar, and A. Sen, "Sustainability of Healthcare Information Exchanges: A Game-Theoretic Approach," Information Systems Research, vol. 27, no. 2, Jun. 2016, pp. 240-258, doi: 10.1287/isre.2016.0626.

[58] R. Bernardi, "Health information systems and accountability in Kenya: A structuration theory perspective," Journal of the Association for Information Systems, vol. 18, no. 12, 2017, pp. 931957, doi: 10.17705/1jais.00475.

[59] M. Dadgar and K. D. Joshi, "The Role of Information and Communication Technology in Self-Management of Chronic Diseases: An Empirical Investigation through Value Sensitive Design," Journal of the Association for Information Systems, vol. 19, no. 2, 2018, pp. 86-112.

[60] I. Dissanayake, S. Nerur, R. Singh, and Y. Lee, "Medical crowdsourcing: Harnessing the "wisdom of the crowd' to solve medical mysteries," Journal of the Association for Information Systems, vol. 20, no. 11, 2019, pp. 1589-1610, doi: 10.17705/1jais.00579.

[61] M. Findikoglu and M. B. Watson-Manheim, "Linking macro-level goals to micro-level routines: EHRenabled transformation of primary care services," Journal of Information Technology, vol. 31, no. 4,
2016, pp. 382-400, doi: 10.1057/s41265-016-0023-5.

[62] E. Klecun, Y. Zhou, A. Kankanhalli, Y. H. Wee, and R. Hibberd, "The dynamics of institutional pressures and stakeholder behavior in national electronic health record implementations: A tale of two countries," Journal of Information Technology, vol. 34, no. 4, 2019, pp. 292-332, doi: 10.1177/0268396218822478.

[63] L. Chen, A. Baird, and D. Straub, "Fostering Participant Health Knowledge and Attitudes: An Econometric Study of a Chronic Disease-Focused Online Health Community," Journal of Management Information Systems, vol. 36, no. 1, 2019, pp. 194229, doi: 10.1080/07421222.2018.1550547.

[64] D. H. Saifee, I. R. Bardhan, A. Lahiri, and Z. Zheng, "Adherence to Clinical Guidelines, Electronic Health Record Use, and Online Reviews," Journal of Management Information Systems, vol. 36, no. 4, 2019, pp. 1071-1104, doi: 10.1080/07421222.2019.1661093.

[65] K. K. Ganju, P. A. Pavlou, and R. D. Banker, "Does information and communication technology lead to the well-being of nations? A countrylevel empirical investigation," MIS Quarterly, vol. 40, no. 2, 2016, pp. 417-430, doi: 10.25300/MISQ/2016/40.2.07.

[66] R. Bernardi, S. Sarker, and S. Sahay, "The role of affordances in the deinstitutionalization of a dysfunctional health management information system in Kenya: An identity work perspective," MIS Quarterly, vol. 43, no. 4, 2019, pp. 1177-1200, doi: 10.25300/MISQ/2019/14187.

[67] A. Essén and S. W. Värlander, "How technologyafforded practices at the micro-level can generate change at the field level: Theorizing the recursive mechanism actualized in Swedish rheumatology 2000-2014," MIS Quarterly, vol. 43, no. 4, 2019, pp. 1155-1176, doi: 10.25300/MISQ/2019/12164.

[68] W. Zhang and S. Ram, "A Comprehensive Analysis of Triggers and Risk Factors for Asthma Based on Machine Learning and Large Heterogeneous Data Sources," MIS Quarterly, vol. 44, no. 1, 2020, pp. 305-349, doi: 10.25300/misq/2020/15106.

[69] Q. Ben Liu, X. Liu, and X. Guo, "The Effects of Participating in a Physician-Driven Online Health Community in Managing Chronic Disease: Evidence from Two Natural Experiments," MIS Quarterly, vol. 44, no. 1, 2020, pp. 391-419, doi: $10.25300 / \mathrm{misq} / 2020 / 15102$.

[70] S. Thompson, J. Whitaker, R. Kohli, and C. Jones, "Chronic Disease Management: How IT and Analytics Create Healthcare Value Through the Temporal Displacement of Care," MIS Quarterly, vol. 44, no. 1, 2020, pp. 227-256, doi: $10.25300 / \mathrm{misq} / 2020 / 15085$. 